\title{
The Challenge of 21st Century Leadership: The Transition from "I" to "We"
}

\author{
Gabriela Krstevska1, Sonja Rizoska-Jovanovska²
}

UDC 005.322:316.46"20"

\author{
'ISU “G.R.Derzhavin”, Marshal Tito 77, Sveti Nikole, North Macedonia, gabriella@t.mk \\ ${ }^{2}$ ISU "G.R.Derzhavin", Marshal Tito 77, Sveti Nikole, North Macedonia, \\ sonjarizoska@yahoo.com
}

The exponential growth of science, in all spheres of modern life, is a big challenge for every person, in order to find a way to follow these changes. The belief in the economy, politics, leading elites, as well as in the media is probably at the lowest possible level, not only nationally and regionally, but also globally. Using different communication channels (like social networks as the simplest communication channels) each stakeholder can give negative reviews and comments about an organization. In such difficult and challenging business conditions, the usual methods and theories of management do not work best at all levels of cooperation and action. The reason for this probably lies in the fact that while the world is changing rapidly, transforming itself into new forms, management as a science fails to follow in parallel, the steps of all the changes and processes caused by globalization. The competition for talents in the labor market today, requires additional effort from the management of organizations. If we take into account that fact (from many others), we can clearly see that a "new" time is coming in which managers need to be constantly (re)inventive, both in terms of themselves, as a person, but also in term of managing their organizations, too. For those who want to create the necessary change and adapt to modern functioning, this "journey" can be a significant evolution on an individual, collective and global level filled with many innovations and challenges. The pandemic that brought a major crisis situation at all levels, on the other hand, led to changes in the management methodology. All these crisis situations put the leaders to a huge test to prove, which of them is the real manager in bad times so as in good times, and which remains even a step behind or down, because he cannot face the challenges first as a person himself, and then on the other hand to adapt the employees to the newly imposed working conditions, without disturbing the humanitarian aspect. The "new" time proved to be a time of significant changes that dictate a different culture of living, different experiencing things, re-examining all the trends that are aimed at a kind of growth and development of the person, that steps with enormous speed through all changes and processes, as a being, a person, a motivator, an innovator, a manager, to finally realize that until the "I" didn't turns into the "WE", we cannot talk about any leadership, in context of all the challenges, that only the right manager can face every day.

Keywords: Change management, management, home office, organization

\section{Introduction}

The pandemic we face is questioning traditional ways of working and managing, i.e. managers are wondering how to behave in times of crisis. At a time when the corona 
pandemic and the crisis it brought with it are still not over, some organizations are struggling with the idea to reopen the doors of their offices, not leaving out the measures of social distancing combined with strict hygiene measures. Wherever possible, governments advocate the concept of working from home the so called Home Office concept.

Many organizations and their management have resisted and had big doubts in the time before Corona to introduce new concepts, the new form of work, known today internationally as "New work ". But as much as it seemed as unattainable and unacceptable (by some managers and employees even with resistance) this concept has been shown to have a positive effect on productivity, employee satisfaction, and engagement of employees, as well on their fluctuation.

Despite the unpreparedness of the management, the pandemic still forced many of them to accept at least a part of the New work approach, i.e. the concept of Home office. For some managers the combined work (from home and from the office) was already accepted and applied practice, so the novelty was not a special challenge, but for others, the new situation was a big change, which brought with it repercussions at all levels. For many managers, it was unthinkable to allow their employees to do their job independently, outside the office or workplace, without strict oversight of the work, while keeping employees productive.

Considering that each manager manages in a different way, and that we are all individuals with different characteristics and traits, we faced an imbalance because while some were just trying to discover new ways of managing their employees, others had really great difficulty dealing with the challenge of today's New work.

\section{Management skills and qualities required in the Corona crisis}

First of all, given that there are several management qualities that are particularly important to apply in the Corona crisis, in a word called humanities (qualities), we realized that what is important in managing the current business environment is:

- deep (essential) listening to employees,

- agility and flexibility,

- complete honesty, modesty, patience, calmness,

- willingness to experiment,

- learning from mistakes (own and others),

- Rapid change of direction and mode of operation if necessary.

Probably more than ever we have faced the need to create a climate in organizations in which employees will feel safe. In a direct way, the management is faced with the situation that exactly the management is responsible for creating a sense of security, to provide security, i.e. that none of the employees will be left out, while not allowing themselves to favor one employee over another.

In the current operating conditions, managers need to practice cognitive empathy. Emotional and cognitive empathy, according to Marco lacoboni, are two different sides of the same medallion. These two forms of empathy correspond to the classical psychological dichotomy between type- 1 and type- 2 processes. Type- 1 is more automatic, i.e. pre-reflective, stimulating and inflexible, while type- 2 processes seem laborious, slow, intentional at first, but they are still flexible [1].

If we point out the classic example of emotional empathy as "emotional contagion", it means that emotions spread among people who interact like a virus in a semi-automated and prereflective form. On the other hand, cognitive empathy is a process that requires much more engagement. It presupposes a process that involves "seeing" things from another person's perspective, understanding the other person's motives, accepting the other's point of view, 
and at the same time feeling like the other so that you can think like the other person. (Figure 1).

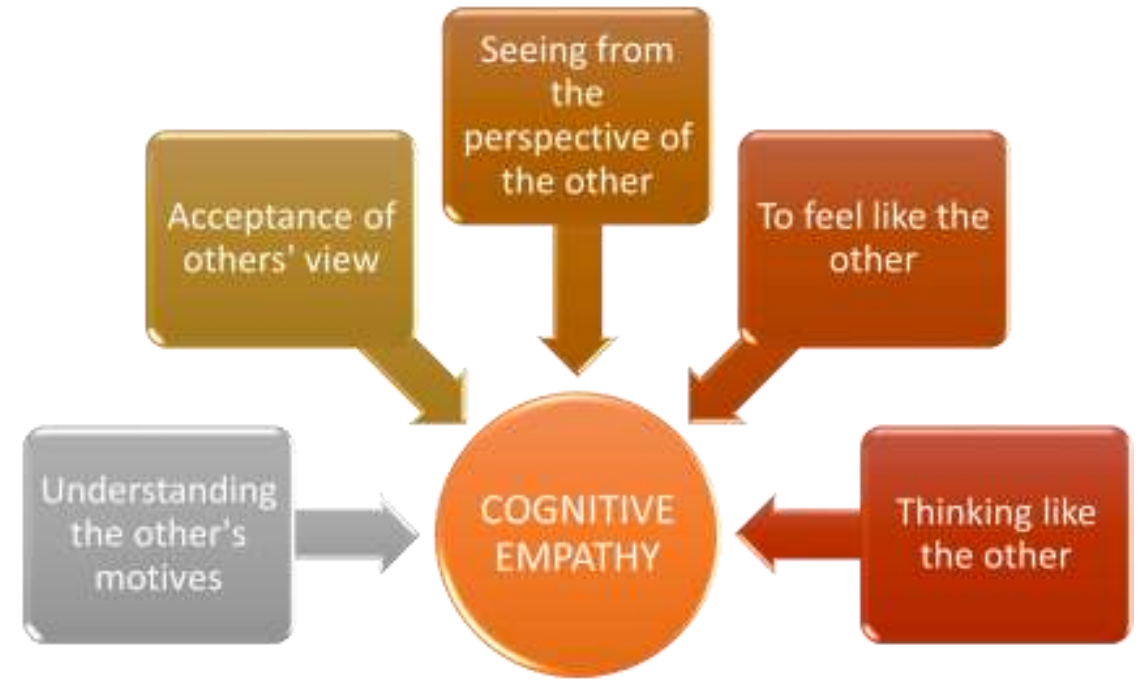

Figure 1: Guidance to cognitive empathy

Cognitive empathy can be most simply explained by the expression "I see what you feel." The fact is that we are all involved in a situation that is completely unpredictable, a situation that has developed and is still developing very complex, which in itself leads to a new situation, where managers need to be able to pay attention first to the organization, then to its internal and external environment and to all stakeholders, and all this, in order to involve all the sides that have some interest (stakeholders) and things in the process to create a sense of connection. In such moments, the need for unity is especially expressed. A person as individual, as a unit, is not able to overcome the obstacles, on its own, without difficulties. Namely, it requires a mutual sense of connection and transition to "WE" and detachment from the "I" approach. In these (un)times it is necessary to literally stand "side by side" not only with employees, but also with customers, suppliers, in fact with the society as a whole.

Due to the complexity of the situation, in today's and current working conditions, the question that arises is: "What are the necessary management skills?"

For managing people and organization, the most important thing is to determine what every individual can do, what strengths she/he has so that they can be properly used in the function of the organization and exactly where this strength will or can make the greatest contribution and impact. The expertise gained through education and training is not something that lasts a lifetime, because it is clearly detected that during the professional life it must be constantly expanded with new knowledge and adjustments, following the trends, renewing what has been learned, through the gained experiences. This is a rule that applies to all professions, where management is not excluded. In managing, active, in-depth and substantive listening is almost underestimated. For managers there is an opinion that they spend over $70 \%$ of their working time in "communication" during their work day. In reality this means communicating various "announcements", "explanations", "giving directions" and similar. On the other hand, communication is not a one-sided process, because without deep listening we cannot talk about managing today in totality.

If we ask ourselves - what is it the essence that separates managers who can successfully deal with the current situation, as opposed to those who cannot, we will probably be able to find more different answers. Some of the skills that are worth mentioning are of course: skills, ability, competence, setting clear goals, empathy, attentiveness, eloquent communication through all possible channels including video conferencing, knowing the strengths and weaknesses of co-workers. Probably one of the most important skills of the modern manager 
in our time is the ability to have trust, i.e. to build relationships filled with mutual trust, which is part of the successful evolution of the entire management process.

Management should also be aware of the fact that some employees are able to be productive at home and to finish their tasks at a high level, but there are also those who without strong leadership simply feel lost in every sense of functioning. In addition to the obvious characteristics in terms of specialist knowledge and expertise, the possibility of independent work, in the conditions of the pandemic, one characteristic is especially pronounced in some employees, and that is the high degree of internal (self)motivation, which seemed to be lacking or did not come in such a great expression in the operating conditions we were been using before the corona crisis.

The author of bestselling books in the field of business and human behavior, Daniel Pink, believes that there are three factors which are important to provide the necessary level of internal motivation in the workplace, and they are:

- Autonomy or opportunity for self-determination

- Perfection / perfectionism in performance

- Fulfilling the goal/goal achievement.

According to Pink, autonomy is the desire of the person to determine itself, and at the same time to decide for itself certain circumstances. It increases the commitment for fulfilling the duties, as opposed to simply fulfilling the assigned obligations. The factor of perfection is the drive of employees to improve themselves, while the third factor is meeting the goal in terms of doing something that has a purpose and is especially important for both, for employees and for management, too. Maybe the whole management is in front of a significant exam, i.e. whether management that understands the impact of these factors will be able to create jobs and responsibilities that will give employees a wide range of freedom not only in performance and action, but also in decision-making, enabling them to decide together - what is the best way for all of them to work in order to achieve clearly defined goals and objectives. Namely, the management should guarantee an appropriate level of challenge, but also an opportunity for employees to develop and learn on a daily basis, which is a great challenge for everyone.

We want to emphasize another important direction given by this author, and that is that managers in times of current crisis should be fair players in the overall change processes. Many studies have shown that employees have lost or have no confidence in leadership at all. Today, we can emphasize that more than ever before, managers need to practice fair relations with all employees. "You need to avoid any belief that there are different rules for the people at the top and other rules for the other people in the organization," said Daniel Pink. A key characteristic of a person who successfully manages the crisis is precisely the conviction and transmission of the important message that we are all in this together. This means that each individual plays according to the same set of rules of the game [2] and therefore the treatment of every individual is necessary, just in the way as we would like to receive it to ourselves.

\subsection{The challenges of working in "New Work" conditions}

Many employees around the world work from home in the Home office. One of the results of this way of working presupposes a future re-examination of the organizations, like:

- what kind of work should be done in collaboration with others, in cooperation, or

- what kind of work can (not) be done individually, synchronized or unsynchronized, and finally,

- what type of work will require from people in organizations to work physically together, and which type will not have such claims.

It is extremely important for the management to discover what each of the employees can do individually, what are its strengths and based on it, to use this employees' strength where it 
can make the greatest contribution to the organization. If an employee is managed in a way by attempting to eliminate his weaknesses, an average performance reduction of around $27 \%$ is usually obtained. On the other hand, when its strengths are promoted and used, an average performance increase of $36 \%$ is obtained [5]. It is such a wide range of difference, which points to an enormous number of irregularities that certainly lead to the separation of the achievement of the common goal, followed through the path for its achievement of the organizational goal.

When motivating employees, it is not enough to just delegate the responsibilities and tasks that are generally below the intellectual level and abilities of the manager. It is necessary for managers to separate themselves from performing tasks and responsibilities that they personally consider challenging and find them exciting, and to start leaving them to be fulfilled by subordinates.

Management offers a certain kind of vision and higher goals that should be within the reach of the entire organization. Every individual in the organization needs to be able to formulate the reason why she/he as an individual does and works something, why that what she/he is doing is something that is exciting for this person and finally why it would be worthwhile for this person to invest sweat, tears and blood, all in order to achieve that higher common goal. All this imposes to the management the need to communicate regularly, so that each and every employee feels involved in the process, but also the employee to be aware of his value to the organization and that the contribution he makes, is not only appreciated, but also valued.

Something that is necessary for the organizations to do in this (un)time is to learn a significant lesson from this "young and unknown" crisis we are still facing with, to see exactly the input of their teams, by discovering and determining at the same time, which departments in their organization (despite quarantines and lockdown, as well as during the Home Office) proved to be "very good", even during the newly imposed operating conditions. Those managers and leaders who have been able to maintain a high level of performance and productivity by employees, at the same time, maintaining a positive work atmosphere, are the best people in the organization and exactly for this individuals, the organization should give the maximum to keep them to stay a part of it.

In this era of "New Work", it is more important than ever to select people who have the necessary skills, while not forgetting to promot these individuals. But also, it is necessary to give employees support at all levels (organizational and personal) in order to get everyone through this crisis without major consequences, with a common goal to build a successful future for the organization, but in a way to have a positive impact on the society as a whole.

Organizations, in order to be able to get out of the Corona crisis, as little as possible damaged by the consequences, need managers who will develop a culture based on trust. This would mean creating a work environment in which employees will have the opportunity to manage themselves, by creating a culture in which every day learning will be something that is understandable, with the achievement of a higher goal being at the center of every action and activity. All this is in strong contrast to the selection and promotion of people based on their high level of technical expertise.

The next necessary steps would be to make analyzes and evaluations of those individuals, employees who have shown good results, as well as those who have shown potential for their own further development and their segregation from the others, based on performance and productivity. In this way, the organization will become an integral part of the group of those organizations that have successfully dealt with the Corona crisis and have proven capable of withstanding the problems caused by the crisis. On the other hand, an open analysis is necessary to ensure that the results from the inputted effort and endeavor will be taken into account, so there will be no need to bypass the need to make appropriate decisions. The future of the organization, and thus the future of society as a whole, will depend on the courage of management to make such decisions and to conduct these 
comprehensive analyzes of its employees, which is of great importance for the functioning of the organization as a whole.

\subsection{The true leader od today}

The leader of today is the one who cares about the development of co-workers, employees, the one who has a real interest (not declarative) in human capital and its further development. The true leader manages to develop an understanding of the situation and the work of employees through reliable, credible information. A leader is a person who through active and careful listening involves the people from the organization in the work of the organization, whether it is a certain company, or it is a movement, ideology (political or any other kind). Namely, it is about the fact that people who feel connection and are connected to their organization, will consider it as their own and thus will create a real relationship. Such a connection can only occur if the leader, the manager, strengthens and develops his employees, while releasing and handing over part of the "power", so that each individual understands and accepts its responsibilities. Such an attitude will thus contribute to the successful implementation of the organizational strategy and successful operation. But for success to happen realistically, first of all, human development is necessary, which is not only given to the manager as a necessity where she/he needs to direct, but also given to her/him as a very important segment in order to: successfully work with employees, creates totality in all fields and at the same time to achieve final success for all equally.

In the XXI century, in general, the thing that is required from leaders and from the top management of organizations with a special emphasis on the time we live in at the moment the Corona pandemic, the focus shift precisely from the "I" approach to the "WE" approach. In the working conditions so far, there have been (and still are) emphasized the characteristics of leaders and the principles by which they lead, then their leadership specialized knowledge, their leadership experience. Slowly, but surely (and with the pandemic, even with an intensified course), we are moving towards the need for enhanced effectiveness of the teams.

Effective teams are created and enabled through the successful work of managers, where the manager is the one who makes it possible. Namely, the need to strengthen "WE" is emphasized here, which is of great importance for the whole organization.

Only a diverse team, strengthened by diverse talents, knowledge, skills, experience, can successfully overcome the challenge of a growing number of self-managed organizations that have a horizontal, as opposed to the once strict vertical, hierarchy. But, in order to stimulate this potential, the leader (manager) needs to know how to bring the best knowledge to the team and then, afterwards, to be able to give the team the highest possible autonomy. This all leads to the elaboration of everything that is part of this (r)evolution and thus opens very clearly the question: "Why do they all work here and now?". This is where the most important task of the leader is emphasized - to give meaning, seriousness, importance to the tasks that lead to the fulfillment of all goals and tasks of the organization as a totality.

The source of leaders' motivation towards this approach, can come from different parameters, but still we will emphasize and bring it in connection with the previously mentioned theory of motivation of Daniel Pink:

- From autonomy or opportunity for self-determination, through which the leader is allowed (enabled) to work towards achieving positive results

- From their own satisfaction of technical excellence in performance, which enabled them for the best and most appropriate use of their personal talent in serving the team and the organization as a whole, and

- From fulfilling the personal goal, starting from the importance of the activities, all in order to achieve the company's goals, vision and achievements. 


\section{3. „War" for talents}

There are several misconceptions about human resources management. We often encounter the term "War for Talents" in the literature, which as an expression, means even for itself resistance. Many metaphors of war are still used in the sphere of management of organizations and employees, as if the managers are somewhere in a "trench" and try to "overcome" or "defeat" the enemy with a certain tactic. The background to the various militaristic expressions probably comes from the importance and position of the leader in military Businesses, in their work and functioning, have taken over many practices from the military: ranking (by rank, i.e. by function), setting a chain of command, execution without questioning, but also speech and the manner of addressing and communicating. And here, in fact, it turns out that the time has come to reconsider the transition from "I" to "WE".

An appropriate example of the positivity that can result from the "WE" approach is the first photograph of the "shadow of a black hole" in the Universe taken on April 10, 2019. This image has been successfully taken and created thanks to six radio telescopes from different countries: Chile, European countries, Hawaii, the South Pole, countries with different arrangements (democratic and autocratic), which have used their forces to jointly make the impossible possible. Prior to this historic astronomical event, which involved more than 200 astronomers from 13 institutes, none of these telescopes were able to take this image on their own. Together, moving from "I" to "WE", the team was able to build a virtual telescope whose signal reached a magnification of two million times, enough to see a tennis ball on the moon.

All this leads only to a common conclusion, that without cooperation, no one will be able to build success at the company level, and thus participate in the success of the community and the environment in which the organization operates and works, nor will we all be able to deal with climate change, dealing with hunger, and the consequences of the pandemic we are facing. And therefore, so inherent in all of this, the task of management, especially human resource management, is for the "ordinary" people in the organization - to encourage them to create and achieve great results.

But at this point, it all starts within the person. Each individual should ask himself/herself several important questions and give himself/herself the right answers in terms of: "What are my talents and abilities and how well do I know myself? In what direction do I want to use my professional energy? Do I have talents that I use in my free time, which I can use for professional purposes, too? How and why should I enter a "flow" state (because this state leads to increased satisfaction and better performance)? "

If a person is a leader in the true sense, these questions should be asked first to her/himself and then to the team members. The meaning of this "self" re-examination lies precisely in the desire to achieve exceptional performance.

\section{Conclusion}

It can be expected that many will ask themselves what is needed for the leading structures in the organization to make the transition from "I" to "WE". Does it require a different attitude towards themselves, as well as towards the environment that surrounds them? Will it be possible to prescribe certain rules, directions, propositions for this passage? The transition will be conditioned (and therefore expected to emerge) by the mix of the public pressure and the change in the acceptance of the business as a whole and the leadership as an integral part of it. At the same time, it will be extremely important to recruit talent, which is necessary to be kept in organizations and to be further developed, and lastly, it is necessary to remove male chauvinism in the business world. With such changed and new views, understandings and practices, the "self-centered leadership" will be unthinkable and unsuccessful.

The time after World War II, in terms of management, was a time of survival. Then followed the time of social ascent to a certain degree of functioning. Today, the 21 st century, is a time when the economy needs to be positioned solely in the service of people, the community and 
the planet as a whole. Environmental sustainability is one of the basic ingredients of current and future success, and should not be left out of the so-called "WE" concept, because if businesses do not have an entrepreneurial approach that will improve their environment and enrich it with resources, they will not have "support" for their business (from society, customers, investors and employees). The organizations that will function and act in that way will experience economic benefit.

One day, which we hope will not be too far away, the approach of "WE" by the organizational leadership will become a necessity. Then all of us will be able to overcome all the global challenges we face. At the end, all this will be a great lesson for every single one, that everything depends only on us.

\section{References}

1 lacoboni M., Affektive und kognitive Empathie sind zwei Seiten derselben Medaille http://www.creatingconnections.nl/affektive-und-kognitive-empathie-sind-zwei-seiten-derselbenmedaille.html 2015 April

2 Weier H.M, Managing During Crisis: 4 Key Takeaways, https://blog.workday.com/enus/2020/managing-during-crisis-4-key-takeaways.html, 2020 April

3 https://www.humanresourcesmanager.de/news/leadership-fuehrung-in-zeiten-von-corona.html

4 Glaser, J. E. (2005). Creating WE. Avon USA: Platinum Press an imprint of Adams Media, 2005

5 Zugar, E. G., Vom Ich zum Wir: Das Anforderungsprofil der Führungskräfte im 21. Jahrhundert. (D. A. Hildebrandt, Interviewer), 2020

6 Abeysekera, I. (2008). Intellectual Capital Accounting: Practises in a developing country, Routledge, Oxon. Routledge.

7 Amadeo, K., \& Anderson, S. G. (2020, 09 27). www.thebalance.com. Retrieved from Labor Force and Its Impact on the Economy: https://www.thebalance.com/labor-force-definition-how-it-affectsthe-economy-4045035

8 Armstrong, M. (2011). Armstrong's Handbook of Strategic Human Resource Management - 5th edition. London: KoganPage.

9 Bauer, T., \& Erdogan, B. (2012). An Introduction to Organizational Behavior (v.1.1). ladrbucket.org.

10 Brinckmann, J. (2007). Competence of Top Management Teams and Competence of Top Management Teams and Success of New Technology-Based Firms A Theoretical and Empirical Analysis Concerning Competencies of Entrepreneurial Teams and the Development of Their Ventures. Wiesbaden: Deutscher Universitäts-Verlag.

11 Eidemüller, D. (2019, 04 10). www.weltderphysik.de. Retrieved from Erstes Foto eines Schwarzen Lochs: https://www.weltderphysik.de/gebiet/universum/news/2019/erstes-foto-eines-schwarzenlochs/

12 IFAA-Institut für angewandte Arbeitswissenschafte. (2019). www.arbeitswissenschaft.net. Retrieved from Wissensmanagement kompakt: https://www.arbeitswissenschaft.net/fileadmin/Bilder/Angebote_und_Produkte/Broschueren/20193-27_ifaa_Wissensmanagement_kompakt_2.Auflage.pdf

13 Wortmann, C., \& Müller, I. (2020, 07 10). https://www.humanresourcesmanager.de. Retrieved from Führung in Zeiten von Corona: https://www.humanresourcesmanager.de/news/leadershipfuehrung-in-zeiten-von-corona.html 